\title{
A STUDY OF THE ACTIVITY OF SOCIAL ENTERPRISES IN BULGARIA
}

\author{
R. Martinov*, E. Maslarova, K. Benkova \\ Department of Social Activities, Medical Faculty, Trakia University, Stara Zagora, Bulgaria
}

\begin{abstract}
Many companies in Bulgaria are defined themselves as Social enterprises (SE). The process of arising of new SE and their stop of working is a significant challenge. The situation with SE is very dynamic and their real status should be studied to estimate their impact on the Bulgarian economy. Here we describe the real picture of SE in Bulgaria, based on officially published data. In result of data analysis we make conclusions and estimations in order to stabilize these processes. The strong dominance of Sofia (Capital) was detected in both Non-financial (NFE) and Non-for-profit (NPE) sectors of SE. It could be further ascertain if the operations are really in Sofia city or only their registration. Lightly positive trend was found in the number of both NFE and NPE. Highly negative was the trend in the number of employees engaged in NFE, while the NPE sector remained relatively stable. This deviation in employment rate could be explained by a type of funding: NPE were funded predominantly by state or EU projects, while NFE tried to keep the enterprises and balanced by lowering the personnel, probably due to insufficient financing and economic crisis. In conclusion, more attention in needed by the government and the EU regarding the funding of NFE.
\end{abstract}

Keywords: Social enterprise, statistical data, Social economy, Non-Financial Enterprises, Not for Profit Enterprises, Financial indicators

\begin{abstract}
Abbreviations: National Statistical Institute of Bulgaria (NSI); Ministry of Labour and Social Policy of Bulgaria (MLSP); Social enterprise (SE); Non-Financial Enterprises (NFE); Not for Profit Enterprises (NPE)
\end{abstract}

\section{INTRODUCTION}

The subjects of the social and solidarity economy are cooperatives, non-profit legal entities for socially beneficial activities and social enterprises (SE). The principles of the social and solidarity economy include: Advantage of social-economic goals; Association for public and/or collective benefit; Publicity and transparency; Independence from the state authorities; Participation of members, employees in making managerial decisions. Social enterprises address poverty, social exclusion, and unemployment as key social challenges; create jobs, generate tax revenue, benefit society.

\footnotetext{
* Correspondence to: Ruslan Martinov, Department of Social Activities, Medical Faculty, Trakia University, Armeiska 11 Str., Stara Zagora, Bulgaria; +359883386080,e-mail: rmartinov@yahoo.com
}

Public policies support SE development and generate value for community (1).

Following the data of National Statistical Institute of Bulgaria (NSI) (2), the social enterprises identified themselves as social, dividing to:

- Non-financial enterprises (NFE);

- Not for profit enterprises (NPE).

Here we made an analysis of the situation with the Social enterprises of Bulgaria during the period of 2012-2016 on the basis of the published data by MLSP and NSI.

\section{MATERIALS AND METHODS}

The data about the Social enterprises in Bulgaria were taken from the sites of the National Statistical Institute of Bulgaria (NSI) (2) and the Ministry of Labour and Social Policy of Bulgaria (MLSP) (3). Indicators for Social enterprises used were: Number of social enterprises; Number of employees; Region; Economic sector; financial indicators; Employed and employees; Low form of registration. Reports were on enterprises, which identified themselves as social, meeting 
selected criteria. The provided data were analyzed to reveal some dependencies in the behavior of Social enterprises during years 2012-2016.

\section{RESULTS AND DISCUSSION}

An annual statistical survey of social enterprises in Bulgaria started in 2013 by the Ministry of Labour and Social Policy (MLSP) and National Statistical Institute of Bulgaria (NSI) targeting all Non-financial enterprises and Not for profit organizations in the country which were active in the reporting year. The survey was based on the annual accounts of Non-financial enterprises, regardless of whether they draw up account balance, and annual reports of the Not for profit enterprises. The main goal of survey is to identify companies in the social economy and to provide information on certain indicators of social enterprises (3). We used the data for 2012 and 2013 from MLSP. The data for 2014, 2015 and 2016 were provided by NSI.
MARTINOV R., et al.

The reported data from MLSP for 2012 and 2013, and the data from NSI for 2014, 2015 and 2016 were united and were subject of the present study. The provided official information was analysed and leaded to clear conclusions.

\section{NON-FINANCIAL ENTERPRISES}

Here we will analyze the Non-financial enterprises, which identified themselves as social, by different indicators: by legal form; by number of employee; by economic sectors; by region.

\section{Non-financial enterprises by legal form}

The number of Non-financial enterprises by legal form did not change significantly with years studied (small superiority during 2015 compare to 2014 and 2016), with predominant legal form of registration "Under commercial low" (Figure 1). Thus, the number of Nonfinancial enterprises, registered during 2014, 2015 and 2016 is almost constant and stable with proportional distribution by legal form.

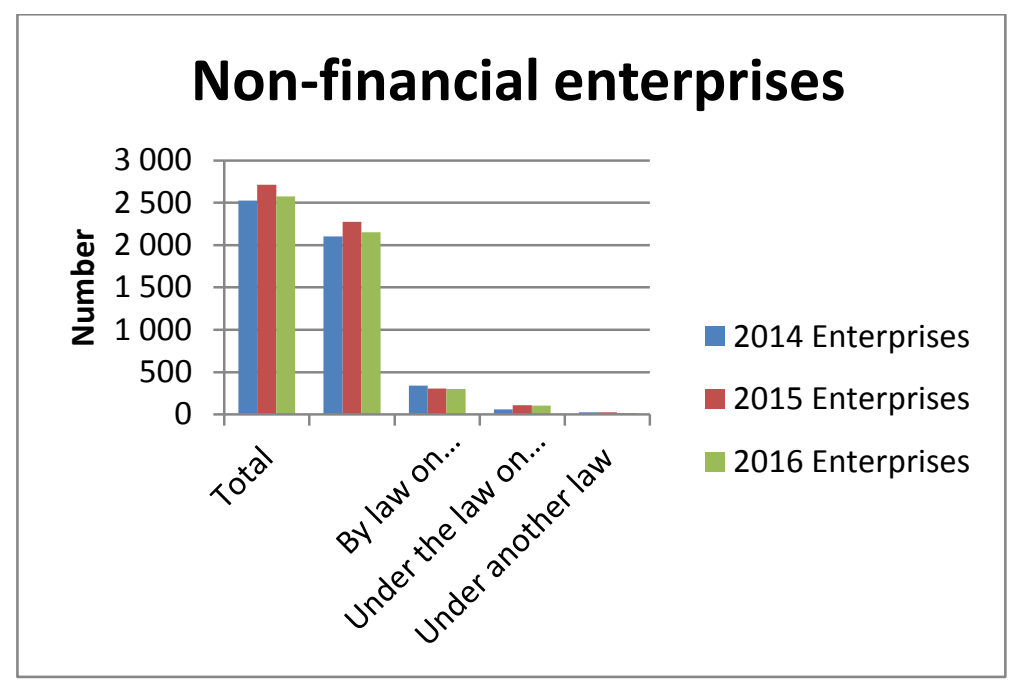

Figure 1. Non-financial enterprises in Bulgaria by legal form of registration. Source data: NSI.

\section{Non-financial enterprises by economic sectors}

Non-financial enterprises by number of employees and by economic sectors

The data on Figure 2 showed that the number of employed people in Non-financial enterprises diminished regularly in the years from 41939 in 2012 to about 17272 in 2016 (32561 in 2013, 28880 in 2014, 23919 in 2015). This dependence could be related to the still ongoing world economic crisis in 2012, reflected also in the Social economy of Bulgaria. The most propagated economic sector with most employed people was constantly the "Manufacturing", followed by the sectors of "Wholesale, retail trade, repair of motor vehicles and motorcycles", and "Agriculture, forestry and fishing", and further by "Water supply" and "Construction", while all diminished constantly from 2012 to 2016. The sectors of "Administrative and support service activities", and "Human health and social work activities" almost did not change within the studied period that could be explained by the predominantly state funding (subsidies) of these sectors. Comparing, the sector "Information and communication" increased slowly the number of employed people during the studied years 20122016 (from minimum 869 in 2013 to maximum 1358 in 2014), due to the highly innovative character of the sector. 


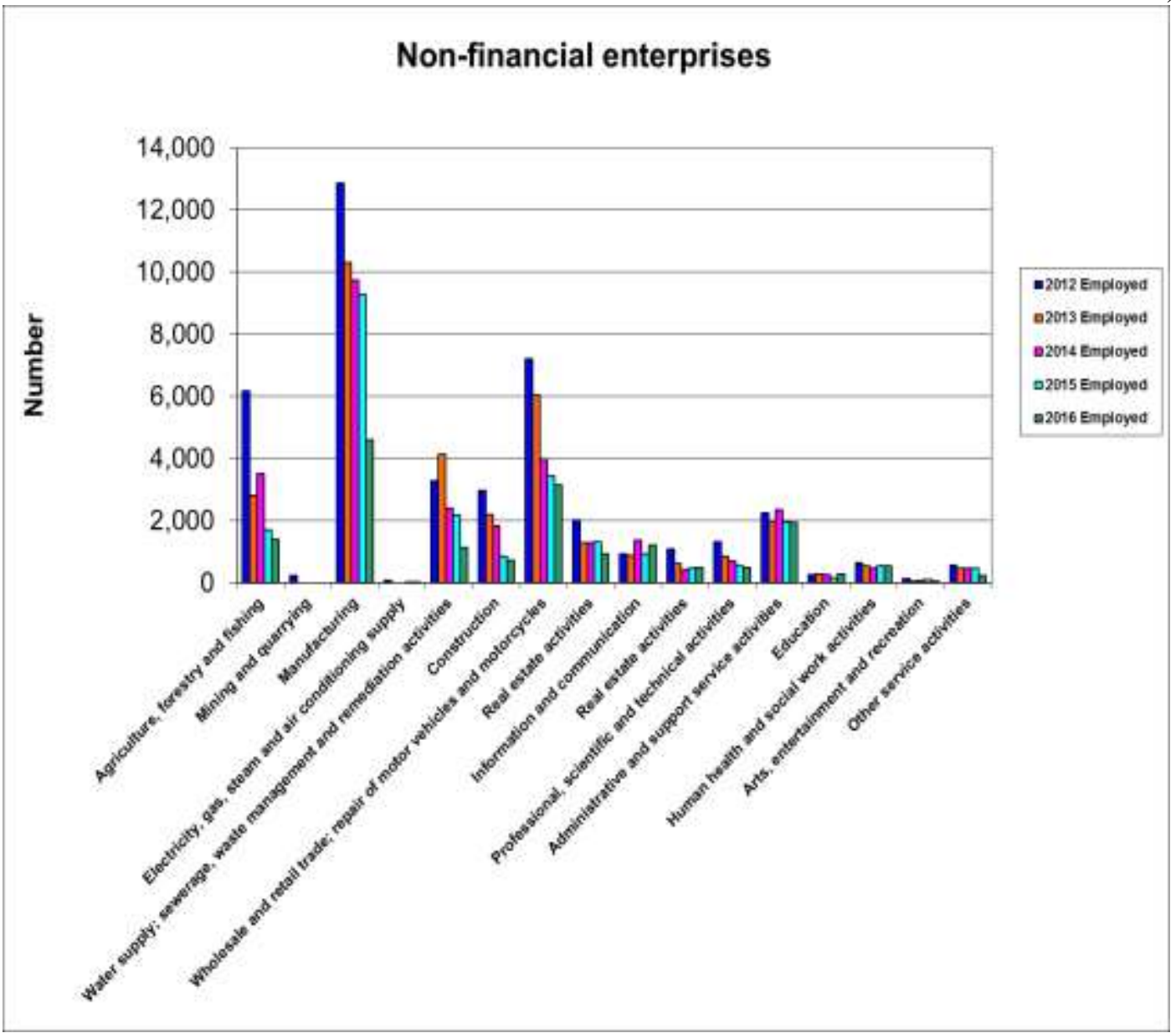

Figure 2. Non-financial enterprises in Bulgaria by economic sector: Number of employees by economic sectors. Source data: NSI and MLSP.

The Non-financial enterprises by number of employees and by economic sectors: the total employed people decreases almost proportionally from 2012 (41939) to 2016 (17 272) (Figure 3). The distribution profile was stable for 2012, 2013, 2014, 2015 and 2016, diminishing by all sectors. Predominant was the sector of Manufacturing, followed by the sectors of "Wholesale, retail trade, repair of motor vehicles and motorcycles", and "Agriculture, forestry and fishing". During 2012 and 2013 the number of employed people was bigger, and decreased considerably in the next years 2014, 2015 and 2016, probably due to the still ongoing financial crisis and resulting decreasing role of social enterprises in economics of Bulgaria.

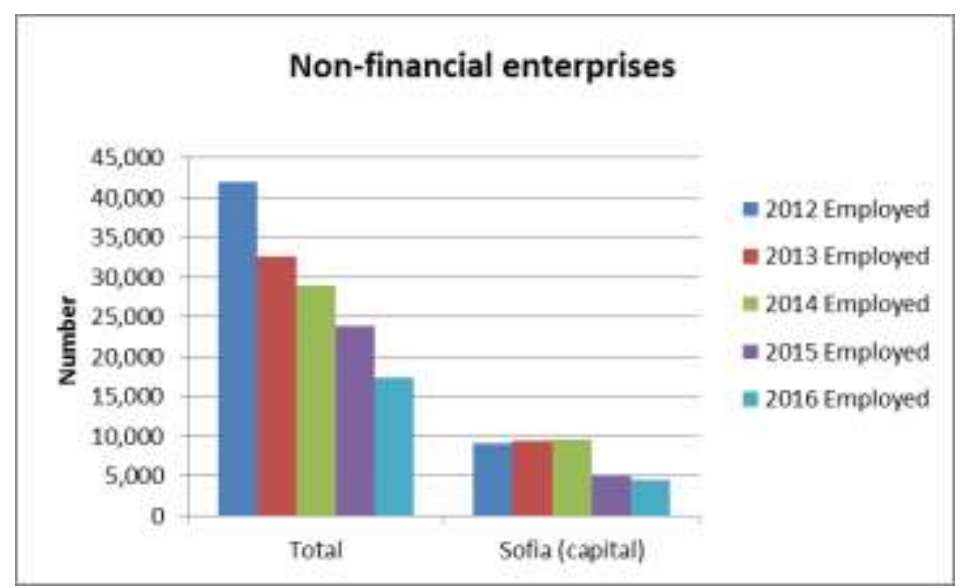

Figure 3. Non-financial enterprises in Bulgaria by Region: Number of Employed people for Sofia (Capital) and Total for Bulgaria. Source data: NSI and MLSP. 
Non-financial enterprises by number of Enterprises

The Total number of Enterprises was almost constant during years 2012-2016 (between 2717 in 2012 and 2577 in 2016) (Figure 4). A minimum was detected in 2013 (2046 enterprises). The sector with most enterprises was the "Wholesale and retail trade; repair of motor vehicles and motorcycle" with about 1000 enterprises (between 964 in 2012 and 1100 in 2014) per year, were the minimum was
MARTINOV R., et al. for 2013 (754 enterprises) (Figure 5). The sector of "Manifacturing" followed, which diminished constantly from 394 enterprises in 2012 to 224 in 2016. The sector of "Real estate activities" was the only one that increased considerable from 269 enterprises in 2012 to 521 in 2015 and 480 in 2016. The specificity by sector was related to the the still ongoing world economic crisis in 2012 and its reflection and consequences on the social economics of Bulgaria.

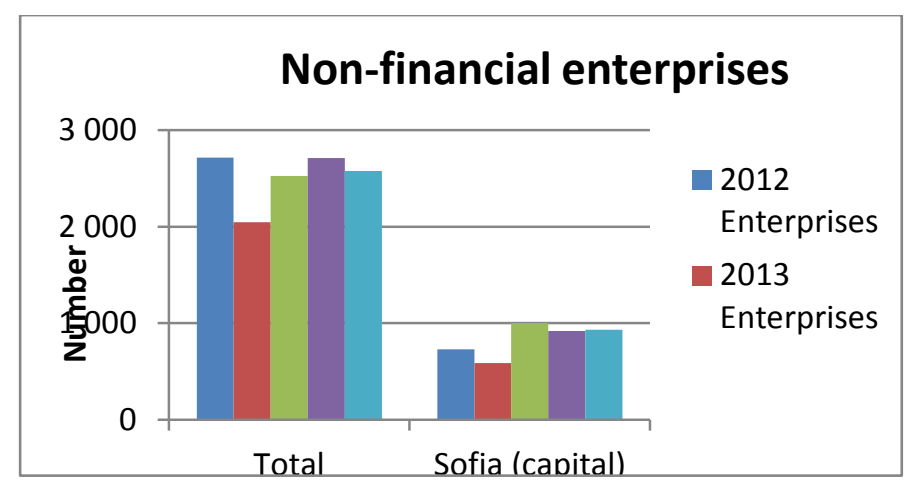

Figure 4. Non-financial enterprises in Bulgaria by Region: Number of enterprises for Sofia (Capital) and Total for Bulgaria. Source data: NSI and MLSP.

In Total, the number of enterprises did not change considerable during the period 20122016, while the Total number of employed people diminished constantly and considerable in this period. Thus, the business could keep the enterprises after the financial crisis, but the number of employed people in these enterprises considerable diminished from
2012, probably because of pear funding and more limited source of finances to employ more people or at least to keep the working places and positions. Thus, the main influence within the studied period was on the working force. By sector, almost in all, the tendency was similar, to keep the enterprises, but to lower the working positions.

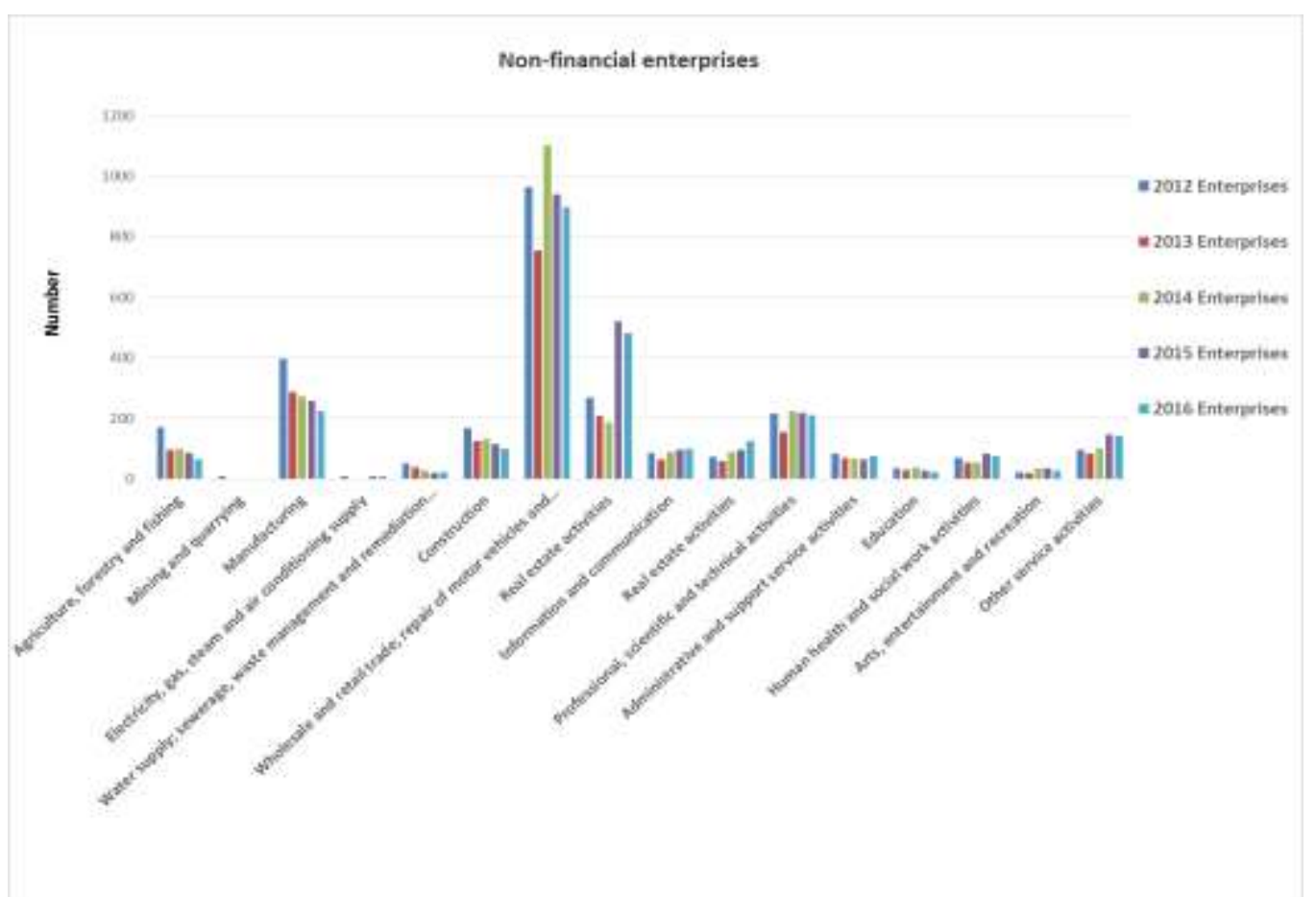

Figure 5. Non-financial enterprises in Bulgaria by economic sectors: number of enterprises by economic sectors. Source data: NSI and MLSP. 


\section{Non-financial enterprises by Region}

Non-financial enterprises by number of employees and by Region

The main part of NFE in Bulgaria is located in Sofia (Capital) as well as the main number of workers employed (Figures 3, 4). Thus, during the period 2012-2016 the number of NFE diminished in 2013 (2046 enterprises), but increased in the next years, both is Sofia capital as well as Total for Bulgaria: this relationship was from about 29\% in 2013 (586 enterprises in Sofia against 2046 Total) to about 40\% in 2014 (1001 enterprises in Sofia against 2526 in Total) (Figures 4, 6). The number of Employed people diminished strongly and constantly during the period in Total (Figure 3), but for Sofia capital this
MARTINOV R., et al. difference was smaller, where during 2015 and 2016 the number of employed diminished about twice, comparing to previous years 2012, 2013 ad 2014, thus increasing the share of employed people up to $26 \%$ in 2016 (4441 employed in Sofia against 17272 Total in Bulgaria) and 33\% in 2014 (9615 in Sofia against 28880 Total) from Total employed in Bulgaria. In conclusion, the sector of NFE stays relatively stable by number of enterprises (between 2046 and 2717). In contrary, there was a strong decrease of the number of employed people (2.4 fold) Total in Bulgaria (from 41939 in 2012 to 17272 in 2016), mostly in regions of the country, and less in Sofia city ( 2 fold) (from 9102 in 2012 to 4441 in 2016).

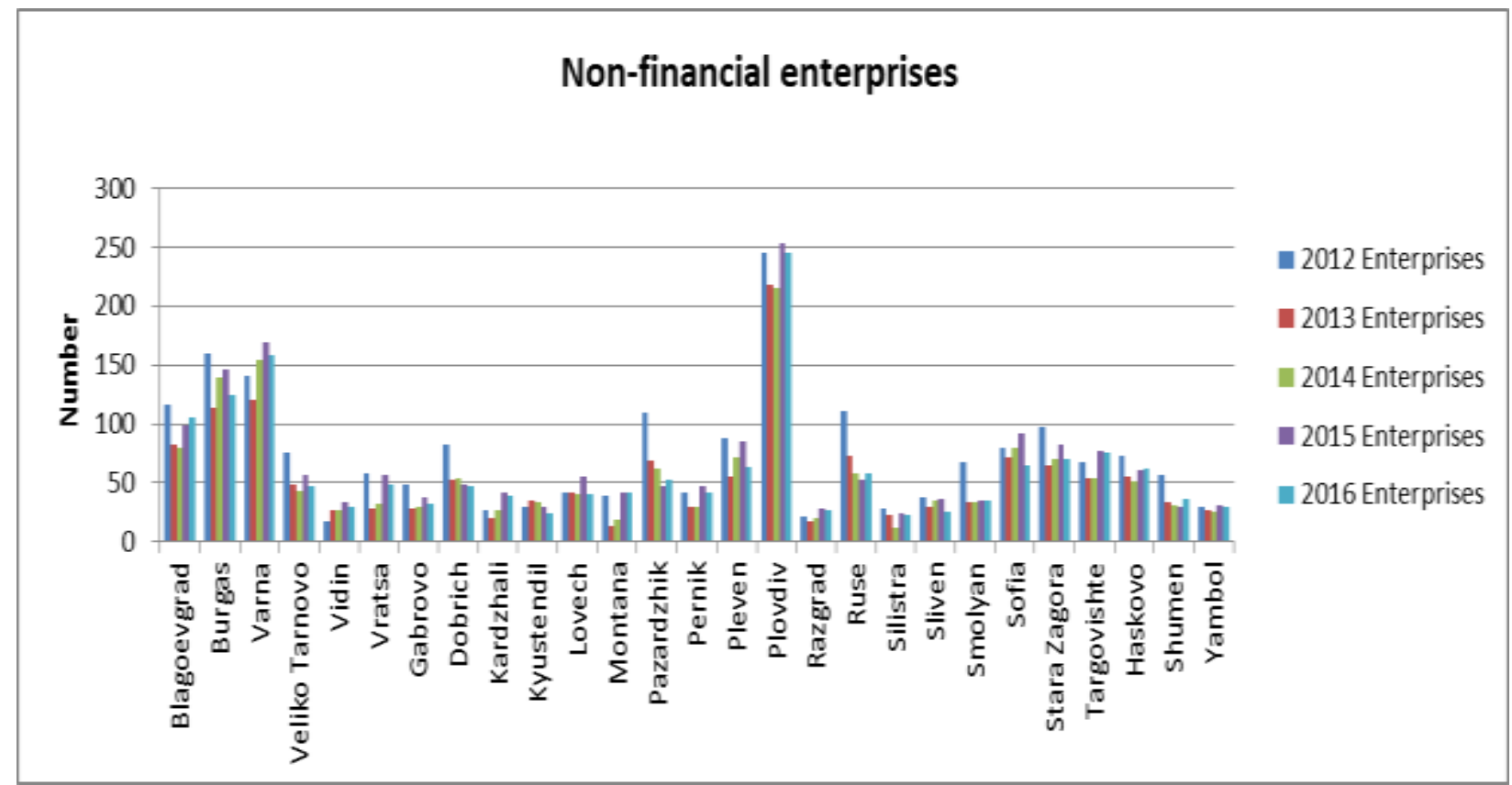

Figure 6. Non-financial enterprises in Bulgaria by Region: Number of enterprises by Region. Source data: NSI and MLSP.

Non-financial enterprises by number of Enterprises and by Region

In the regions of Bulgaria, the number of NFE did not change considerably in 2012-2016

(Figure 6), these number diminished from 2012 in the regions Blagoevgrad, Burgas, Veliko Tarnovo, Dobrich, Pazardzhik, Ruse, Smolyan, Stara Zagora, Shumen. The region Plovdiv is leading with more than 216 NFE per year, followed by Varna with more than 121 NFE per year, and further regions of Burgas, Blagoevgrad, Sofia region, Stara Zagora.
The Regions with most number of employed people were Blagoevgrad, Plovdiv and Varna (Figure 7). From 2012 the number of employed people diminished in almost all regions, most considerable in Plovdiv, Vratza, Lovech, Pleven Smolyan, Stara Zagora, Shumen, due to the still ongoing financial crisis in 2012. Thus, the number of employed people varied with years in all regions. The regions with less employed people were Vidin, Razgrad and Yambol. 


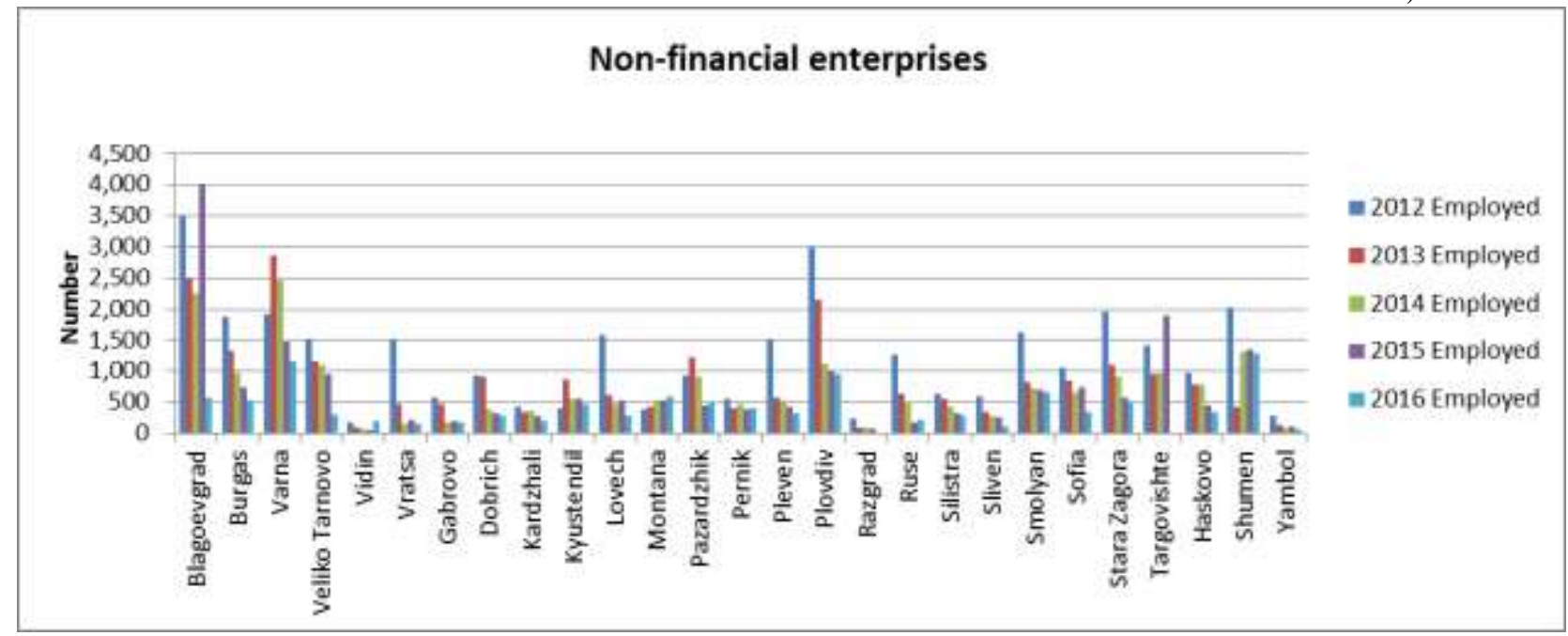

Figure 7. Non-financial enterprises in Bulgaria by Region: Number of Employed people by Region. Source data: NSI and MLSP.

Finally, the number of NFE stayed almost unchanged in the period 2012-2016, while deviations were registered in the number of employed people by regions. The less affected by these fluctuations in NFE were regions of Sofia Capital and Varna, especially in the level of employment, that could be explained with higher availability of human resources or higher population.

The Total number of employed people in NFE diminished strongly and constantly from 2012 to 2016. The number of employed was much more in Sofia (Capital) than in other regions that were comparable each with other.

\section{Financial indicators 2012-2013}

Some Financial Indicator for 2012 and 2013, reported by MLSP, are shown of Figure 8 . The Financial Indicators increased in 2013, comparing to 2012, except for the indicator "Value added by factor costs", were the value slowly lowers in 2013.

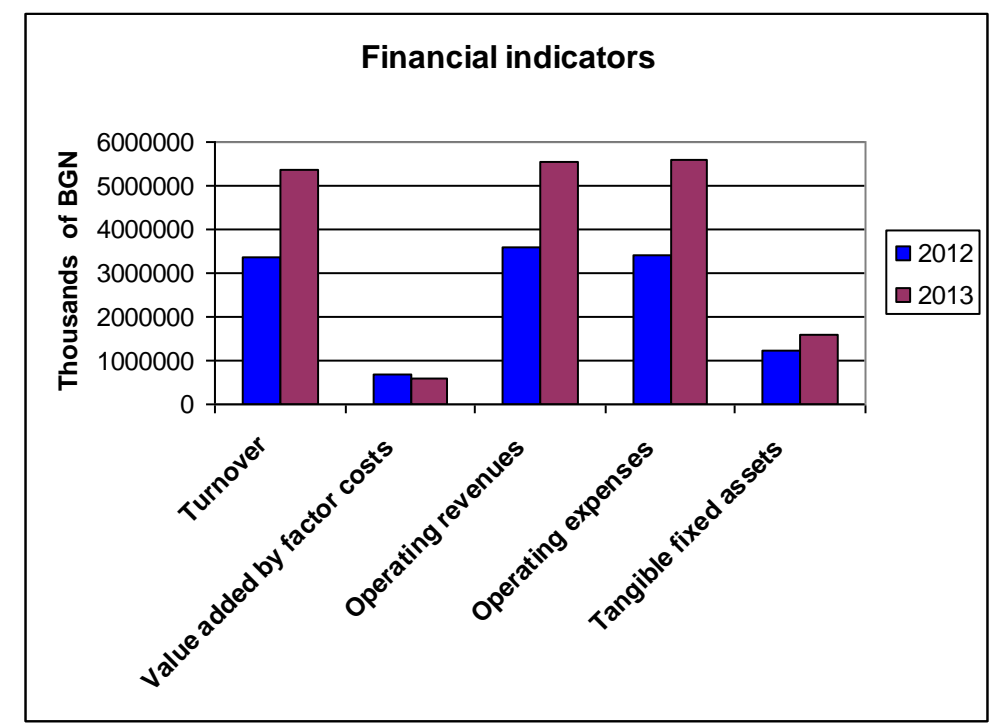

Figure 8. Non-financial enterprises in Bulgaria - Financial indicators for 2012 and 2013. Source data: MLSP.

\section{NOT FOR PROFIT ENTERPRISES}

Not for profit enterprises, which identified themselves as social, were sorted by number of employees, by Region and by legal form.

\section{Not for profit enterprises by legal form}

The profile of legal form of NPE rested unchangable within years 214, 2015 and 2016 (Figure 9): the predominant form of registration was the Low for non-profit total entities (Low for non-profit legal entities: associations, followed by foundations). 


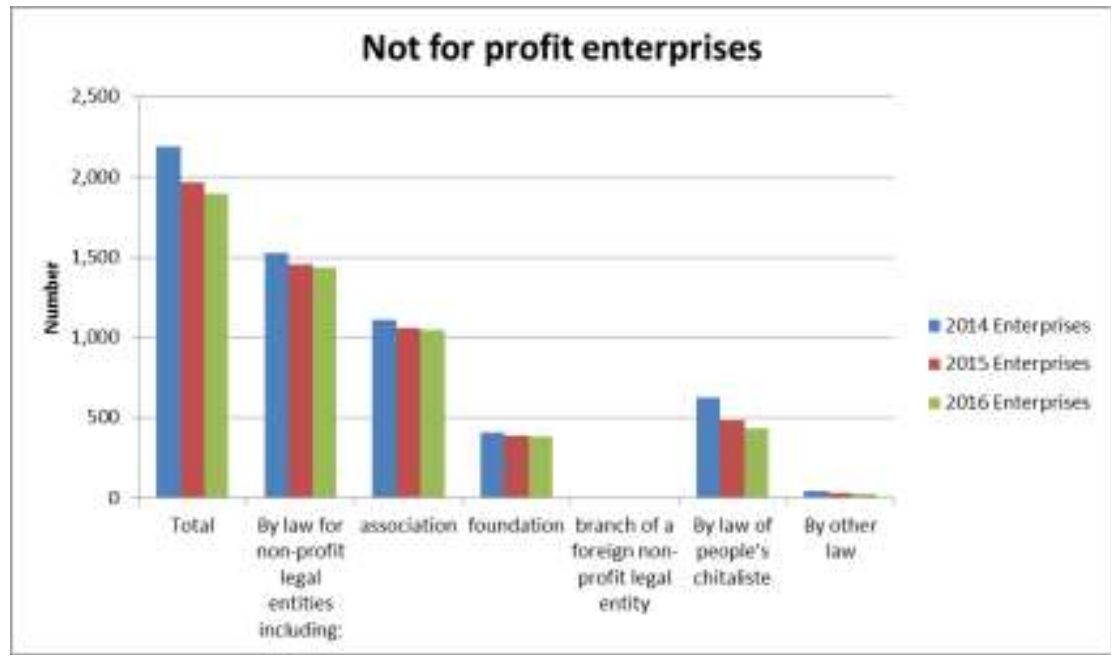

Figure 9. Not for profit enterprises in Bulgaria by legal form. Source data: NSI.

\section{Not for profit enterprises by region}

Not for profit enterprises, which identified themselves as social, by number of employees and by Region

The number of Employed people in Sofia Capital was about half from the Total employed people in NPE in Bulgaria during 2012-2016 (or up to
3355 in Sofia from 7224 Total in 2014) (Figure 10). The number of employed people in NPE was relatively stable in regions (Figure 11): leading Varna, followed by Blagoevgrad, Plovdiv, Stara Zagora, Veliko Tarnovo. Less employed people in the NPE were in Dobrich, Kardzhali and Pernik.

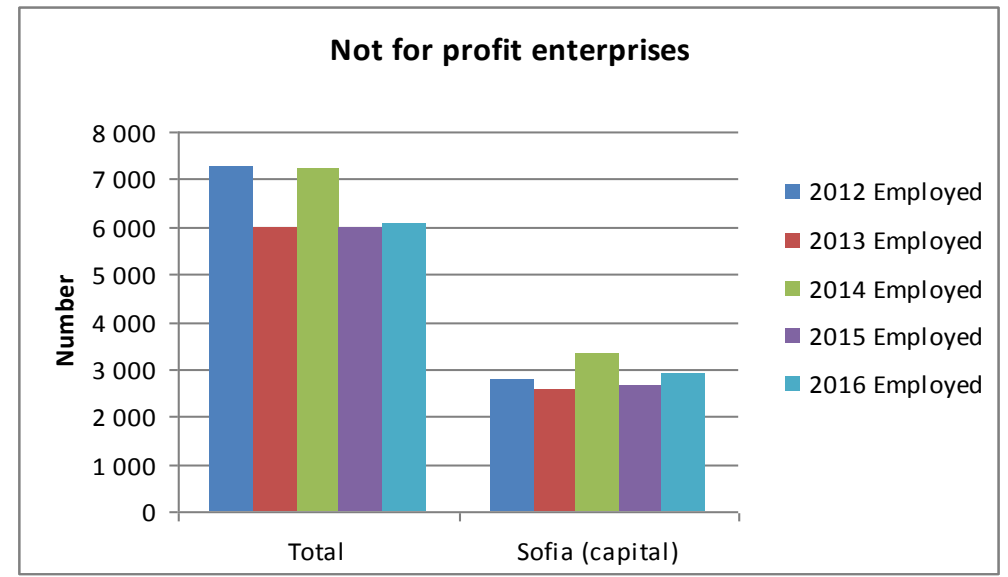

Figure 10. Not for profit enterprises in Bulgaria by Region: Number of Employed people Total for Bulgaria and Sofia (Capital). Source data: NSI and MLSP.

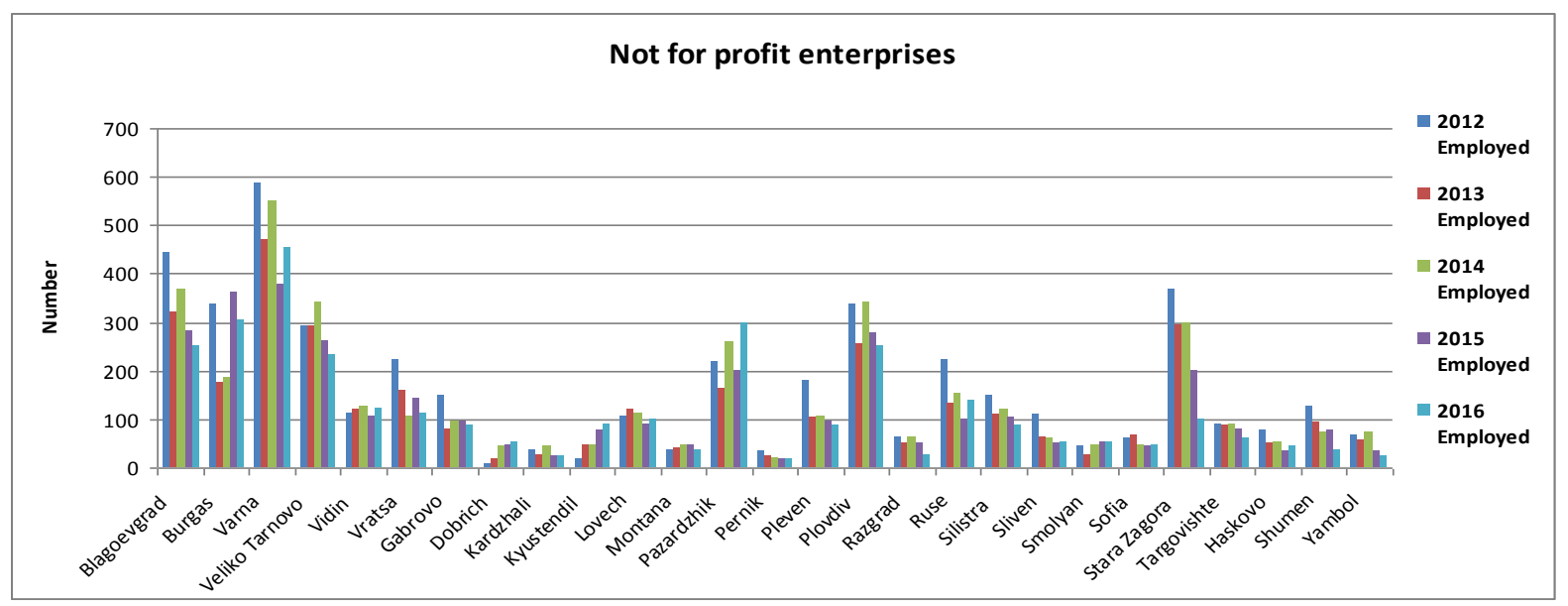

Figure 11. Not for profit enterprises in Bulgaria by Region: Number of Employed people by Region. Source data: NSI and MLSP. 
Not for profit enterprises, which identified themselves as social, by region

The profile of NPE did not change considerable within the years 2012-2016: again a minimum of number of NPE was registered in 2013 (1566 Total), following the still ongoing world economic crisis in 2012 (2155 Total) (Figures 12, 13). The NPE were located
MARTINOV R., et al. predominantly in Sofia Capital (about $1 / 3$ from Total in Bulgaria) or 696 enterprises in Sofia from 2194 Total in 2014 (Figure 12). High was the concentration of NPE in the large regions (big cities with high population) (Figure 13): Varna, Stara Zagora, Plovdiv, followed by Burgas and Blagoevgrad.

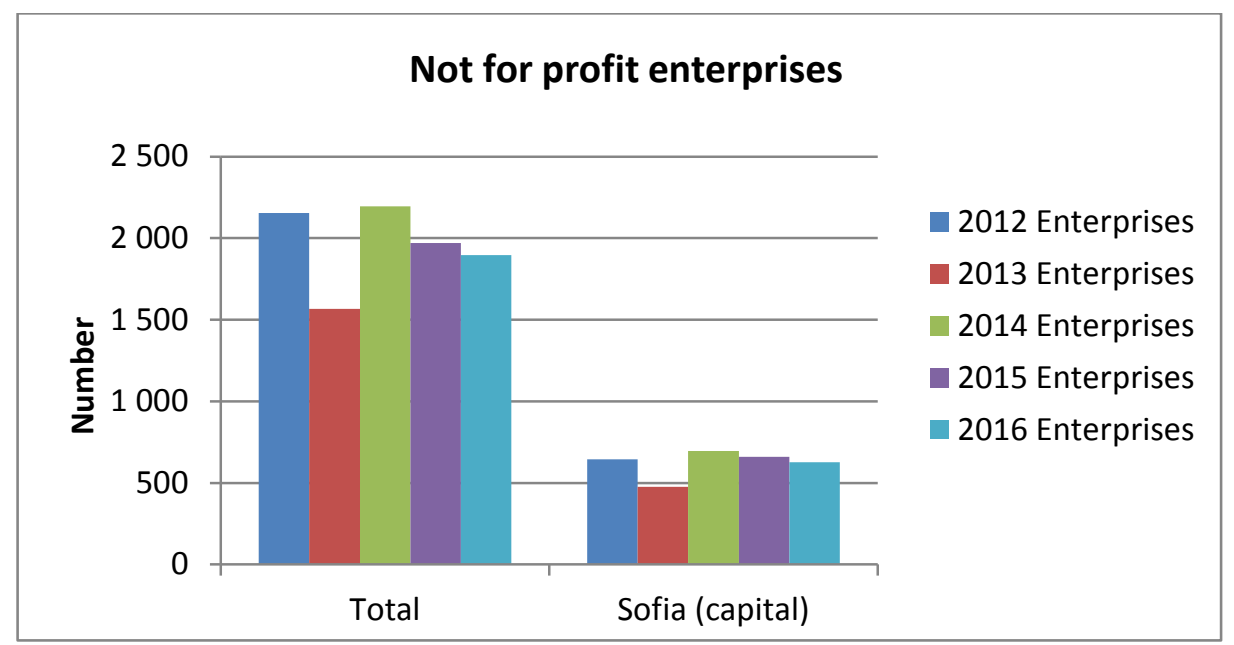

Figure 12. Not for profit enterprises in Bulgaria by Region: Number of enterprises Total for Bulgaria and Sofia (Capital). Source data: NSI and MLSP.

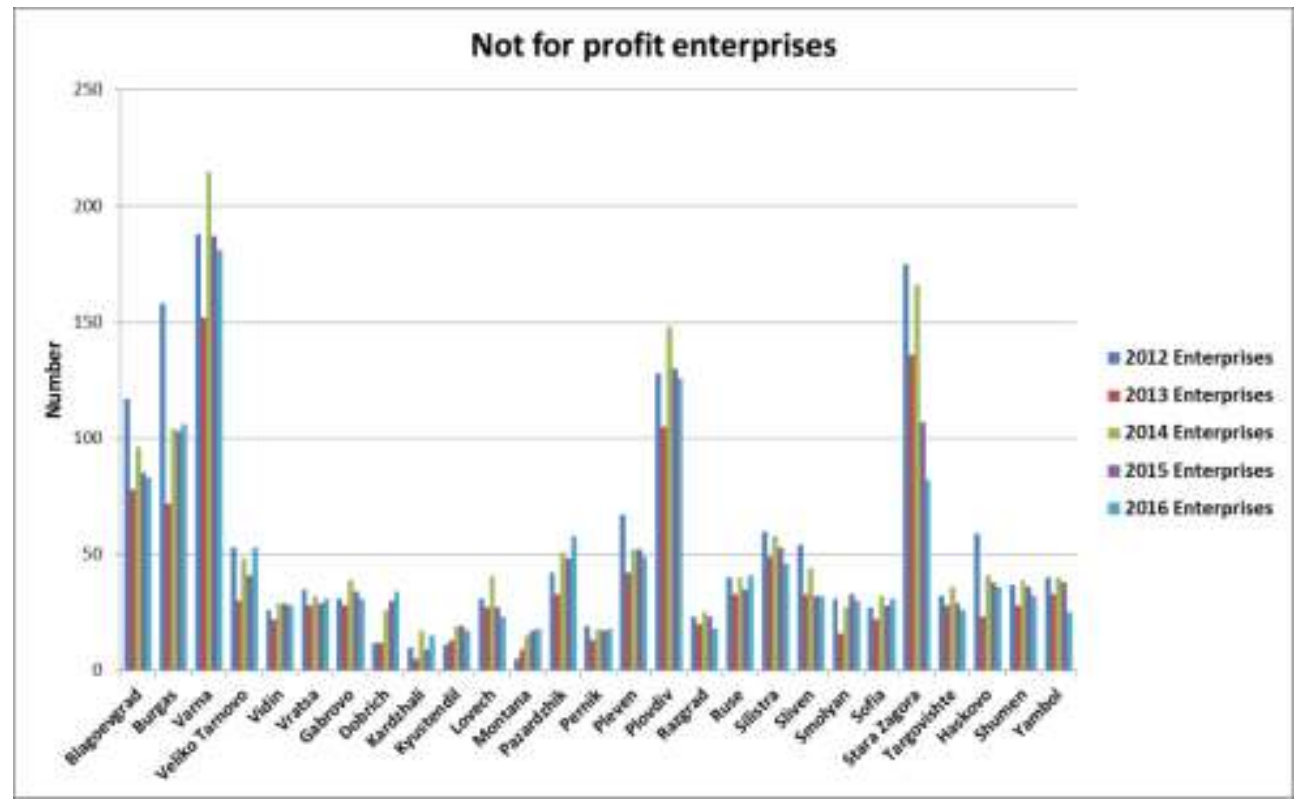

Figure 13. Not for profit enterprises in Bulgaria by Region: Number of enterprises by Region. Source data: NSI and MLSP.

In result, in 2012-2016 the Total number of registered social enterprises NFE and NPE did not differ considerable, while the Total number of employed people was much more in NFE, but decreased strongly during the period, compared to NPE that was relatively stable by the level of employment. These differences could be explained by the different ways of funding of NFE and NPE: NFE balanced by lowering the personnel, probably due to noneffective and insufficient funding, while NPE had more stable financing, relying to EU and state programs that make them more stable in rapport of the personnel.

\section{CONCLUSIONS}

Strong dominance of Sofia (Capital) was detected in both Non-financial and Non-for- 
profit sectors of SE. It could be further ascertain if the operations are really in Sofia city or only their registration is there, while working country-wide.

Lightly positive trend during 2012-2016 was found in the number of both Non-financial and Non-for-profit enterprises, regardless the minimum in 2013. Highly negative was the trend in the number of employees engaged in Non-financial enterprises, while the number of employees occupied in the Non-for-profit sector remained relatively stable in the studied period 2012-2016. These differences in the employment rate could be explained by the diverse type of funding of both sectors, where the Non-profit sector was funded predominantly by state of EU projects, funding
MARTINOV R., et al. that is not so much available or accessible for the Non-financial sector. In conclusion, more attention in needed by government and EU regarding the funding of Non-financial sector of SE in order to keep the employed people.

\section{REFERENCES}

1. Martinov, R., Policies and challenges for Social entrepreneurship of EU countries. PUBLIC POLICY.BG 10(3):94-102, 2019. http://ejpp.eu/index.php/ejpp/article/view/3 26

2. National Statistical Institute of Bulgaria. http://nsi.bg

3. Ministry of Labour and Social Policy of Bulgaria (MLSP) http://seconomy.mlsp.government.bg/db/en 